\title{
Patients with multiple sclerosis do not necessarily consume more alcohol or tobacco than the general population
}

\author{
Pacientes com esclerose múltipla não necessariamente consomem mais álcool ou tabaco \\ do que a população geral \\ Yara Dadalti Fragoso', Sidney Gomes², Marcus Vinicius M. Goncalves³, Suzana C. Nunes Machado, Rogerio \\ de Rizo Morales ${ }^{5}$, Francisco Tomas M. de Oliveira ${ }^{2}$, João Filipe de Oliveira ${ }^{6}$, Neide R. Simoes Olmo ${ }^{1}$, Monica \\ K. Fiuza Parolin7, Fabio Siquineli ${ }^{6}$, Patrick N. Stoney ${ }^{8}$
}

\begin{abstract}
Objective: Recent papers suggest that patients with multiple sclerosis (MS) are prone to alcohol misuse. This may be due to the combination of a lifelong and disabling disease with a psychiatric profile typical of MS. The objective of the present study was to assess these findings in a culturally different population of patients with MS. Method: The present case-control transversal study assessed 168 patients with MS and 168 control subjects from Brazil. Results: There were no evidence that patients with MS drank more alcohol or, smoked more than did controls. In fact, control subjects had a significantly higher alcohol consumption. The only trait associated to higher alcohol consumption was anxiety, both for patients and controls. Conclusion: Unlike previous reports in the literature, patients with MS in our study did not drink or smoked more than a control population.
\end{abstract}

Keywords: multiple sclerosis, alcohol, tobacco, illicit drugs, anxiety, depression.

RESUMO

Objetivo: Artigos recentes sugerem que pacientes com esclerose múltipla (EM) tem tendência ao abuso de álcool. Isto poderia se dever à combinação de uma doença crônica e incapacitante e um perfil psiquiátrico típico da EM. O objetivo do presente estudo foi avaliar estes achados em uma população de pacientes com EM culturalmente diferente. Método: O presente estudo caso-controle transversal avaliou 168 pacientes com EM e 168 controles, todos brasileiros. Resultados: Não houve evidência que pacientes com EM usassem mais álcool ou tabaco do que os controles. Na verdade, os controles apresentavam um consumo significativamente maior de álcool. 0 único aspecto associado ao maior consumo de álcool foi a ansiedade, tanto para pacientes quanto para controles. Conclusão: Ao contrário de outros dados da literatura, pacientes com EM neste nosso estudo não bebem ou fumam mais do que a população controle.

Palavras-chave: esclerose múltipla, álcool, tabaco, ansiedade, depressão.

Multiple sclerosis (MS) is a lifelong inflammatory, demyelinating and degenerative disease of the central nervous system $^{1}$. The disease typically starts in young adults who will often present depression ${ }^{2}$, fatigue ${ }^{3}$, anxiety ${ }^{4}$, anger ${ }^{5}$ and frustration in addition to hopelessness ${ }^{6}$. The combination of a chronic and disabling disease with this psychiatric profile suggests that patients with MS may be at risk of abuse of alcohol. In addition to compromising physical health, alcohol abuse has serious implications for mental health and cognitive performance, conditions that are both already affected

\footnotetext{
${ }^{1}$ Universidade Metropolitana de Santos, Santos SP, Brazil;

${ }^{2}$ Hospital Beneficencia Portuguesa and Hospital Paulistano, Sao Paulo SP, Brazil;

${ }^{3}$ Centro Hospitalar Unimed, Joinville SC, Brazil;

4 Imperial Hospital de Caridade, Hospital Governador Celso Ramos, Florianopolis SC, Brazil;

${ }^{5}$ Universidade Federal de Uberlândia, Uberlandia MG, Brazil;

${ }^{6}$ Universidade Regional de Blumenau, Blumenau SC, Brazil;

${ }^{7}$ Clínica Neurológica de Curitiba, Curitiba PR, Brazil;

${ }^{8}$ University of Aberdeen, Aberdeen, United Kingdom.

Correspondence: Yara Dadalti Fragoso; Departamento de Neurologia, Faculdade de Medicina, Universidade Metropolitana de Santos; Rua da Constituicao, 374;11015-470 Santos SP, Brasil; E-mail:yara@bsnet.com.br

Conflict of interest: There is no conflict of interest to declare.

Received 23 January 2015; Received in final form 19 May 2015; Accepted 01 June 2015.
} 
by MS. Alcohol misuse may lead to decreased adherence to medical treatment ${ }^{7}$, which will also negatively affect the course of MS. Furthermore, alcohol consumption has been shown to have an inverse dose-dependent association with the risk of men and women developing $\mathrm{MS}^{8}$.

Data on alcohol and drug use among MS patients are rather limited. A survey in the US database NARCOMS identified that, among nearly 9,000 patients, there was a high prevalence of adverse health behaviour ${ }^{9}$. This included smoking, high-risk alcohol intake, obesity and a sedentary lifestyle. In the few papers addressing the prevalence of alcohol misuse in MS cases, consistent values between $14 \%$ and $22 \%$ have been reported $^{10,11,12,13}$. Despite the different methods used by these authors, the values are similar and, although high, they are not necessarily different from those of the general population ${ }^{14}$. As for drug use among MS patients, the data are even more sparse, except with regard to cannabis with medicinal purposes ${ }^{13}$.

The present study addresses the issue of excessive drinking and potential drug use among MS patients, using a case-control method to correct for population factors and cultural behaviour.

\section{METHOD}

This study was approved by the Ethics Committee of Universidade Metropolitana de Santos, SP, Brazil, under the registration number CAAE 37491014.5.0000.5509, in 2014. Patients with MS attending outpatients consultations were invited to participate in this study in six MS units in Brazil. Control subjects matched for age, gender and socioeconomic status were included for each patient entering the trial. Control subjects were obtained from accompanying carers of patients attending the outpatients service due to other diseases (not MS). These control subjects referred to be in good health and not undergoing any treatment for chronic illnesses. Socioeconomic level was assessed according to the Brazilian Institute of Geography and Statistics (IBGE), which provides a scale varying from Al to E in decreasing order of goods and possessions. All participants lived between latitude $18^{\circ} 55^{\prime} 07^{\prime \prime} \mathrm{S}$ and $27^{\circ} 35^{\prime} 48^{\prime \prime}$ and longitude $46^{\circ} 20^{\prime} 01^{\prime \prime} \mathrm{W}$ and $49^{\circ} 03^{\prime} 57^{\prime \prime} \mathrm{W}$. The study design was case-control and cross-sectional.

Each participant was individually interviewed using a set of questionnaires that investigated demographic data and also disease condition for those with MS. All participants were then screened for mood disorders using the Hospital Anxiety and Depression Scale (HAD) ${ }^{15}$. The consumption of alcohol was established using the Alcohol Use Disorder Identification Test (AUDIT scale) ${ }^{16}$. The patients' neurological disability was assessed using the expanded disability scale score (EDSS) ${ }^{17}$.

A brief description of the scales used for assessment in the present study is presented:
- HAD: This is a 14 item scale that scores 0 to 3 points for each item. There are seven items for depression and seven for anxiety and they are presented in a mixed format, i.e., items of depression alternating with items of anxiety. This scale does not allow for diagnoses of anxiety or depression, but it serves as a screening method for population studies.

- AUDIT: The questions are related to the alcohol consumption in the past 12 months. There are 10 questions that score zero to four points, and the higher the consumption of alcohol (and its consequences), the higher is the score value.

- EDSS: This is a disability scale, scoring from zero (normal) to 10 (death by the disease). It progresses with half points, and despite overvaluing gait and ambulation, it is the most used scale to assess MS disability.

Separate and direct questions regarding smoking (past or present) were also included at the end of the interview.

Statistical analysis on the data was carried out using GraphPad Prism. Two-way and one-way ANOVA, Spearman correlation, Kruskal-Wallis test, Mann-Whitney test and Student's $t$-test were used to analyse the results. Significant values were those with $p<0.05$. All data were blindly analysed by one of the authors who was not involved with any other stage of the project.

\section{RESULTS}

Data were collected from 168 patients with MS and 168 control subjects of the same gender and similar age, city, and socioeconomic level. There were no significant differences between these groups. In summary, there were 57 males and 111 females, with a median age of 37 years in each group. The median score for the socioeconomic level was 25 for both groups. The classification system for socioeconomic level ranged from $\mathrm{Al}$ (highest, 46 to 48 points) to $\mathrm{E}$ (lowest, zero to 7 points). A score of 25 represented the middle class B2.

Among the patients, there were 156 cases of relapsing-remitting MS (RRMS), nine cases of secondary progressive MS with relapses (SPMS) and three cases of primary progressive MS (PPMS). Only two patients were not using disease-modifying drugs (DMD). Seventy-four patients had not had any changes to their DMD, while 94 had undergone at least one change to their DMD. The average disease duration was $6.5 \pm 4.6$ years (range 1-30 years, median 5 years). The average EDSS was $1.3 \pm 1.4$ (range zero to 6.5 ).

There were 56 patients using glatiramer acetate (Copaxone ${ }^{\circ}$ ), 65 using interferon beta (23 Avonex, 33 Rebif and nine Betaferon $\left.{ }^{\circ}\right), 22$ using natalizumab (Tysabri ${ }^{\circ}$ ) and 12 using fingolimod (Gilenya ${ }^{\circ}$ ).

Patients with MS presented higher levels of depression $(p=0.001)$ than did controls. The same was not found for anxiety $(\mathrm{p}=0.1)$. 
There were no significant differences in the use of tobacco between patients with MS and controls. However, when the use of alcohol was assessed, control subjects scored significantly higher values on the AUDIT scale $(\mathrm{p}=0.0001)$ than did patients with MS.

Fifty-five percent of the patients with MS scored zero on AUDIT (no use of alcohol at all), and only $3 \%$ scored seven or more points, which represents a strong likelihood of hazardous or harmful alcohol consumption. On the other hand, only $28 \%$ of the control subjects scored zero on AUDIT and $4.8 \%$ scored seven or more points. Only one control subject scored over 20 points, thus indicating alcohol dependence.

Regarding smoking, $23.3 \%$ of control subjects had a past or present history of cigarette smoking, with an average of 12 cigarettes per day. Patients with MS had a similar past or present history of cigarette smoking (24.5\%), but an average of only five cigarettes per day.

When subgroups of patients and controls were analysed, higher prevalence of alcohol intake was observed in those with anxiety in both groups alike $(\mathrm{p}=0.03)$. There was no influence
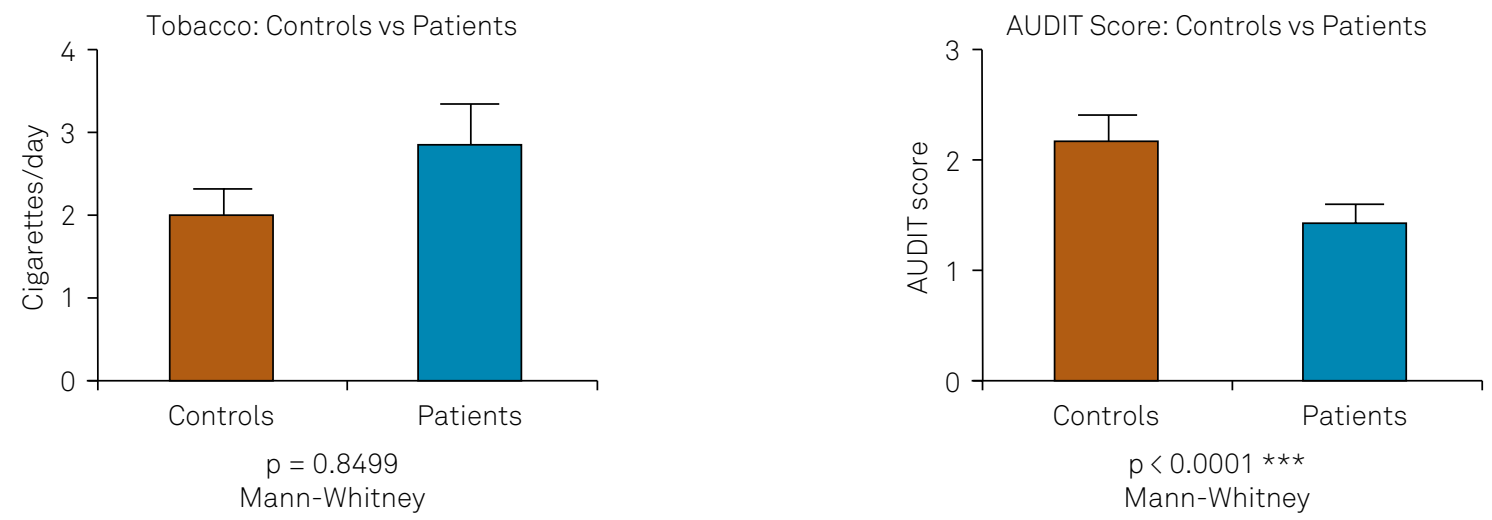

Figure 1. Use of tobacco and alcohol by 168 patients with multiple sclerosis and 168 control subjects matched for gender, age and socioeconomic level. Control subjects drank more alcohol than patients with MS ( $p=0.0001)$. No differences were observed in the use of tobacco.
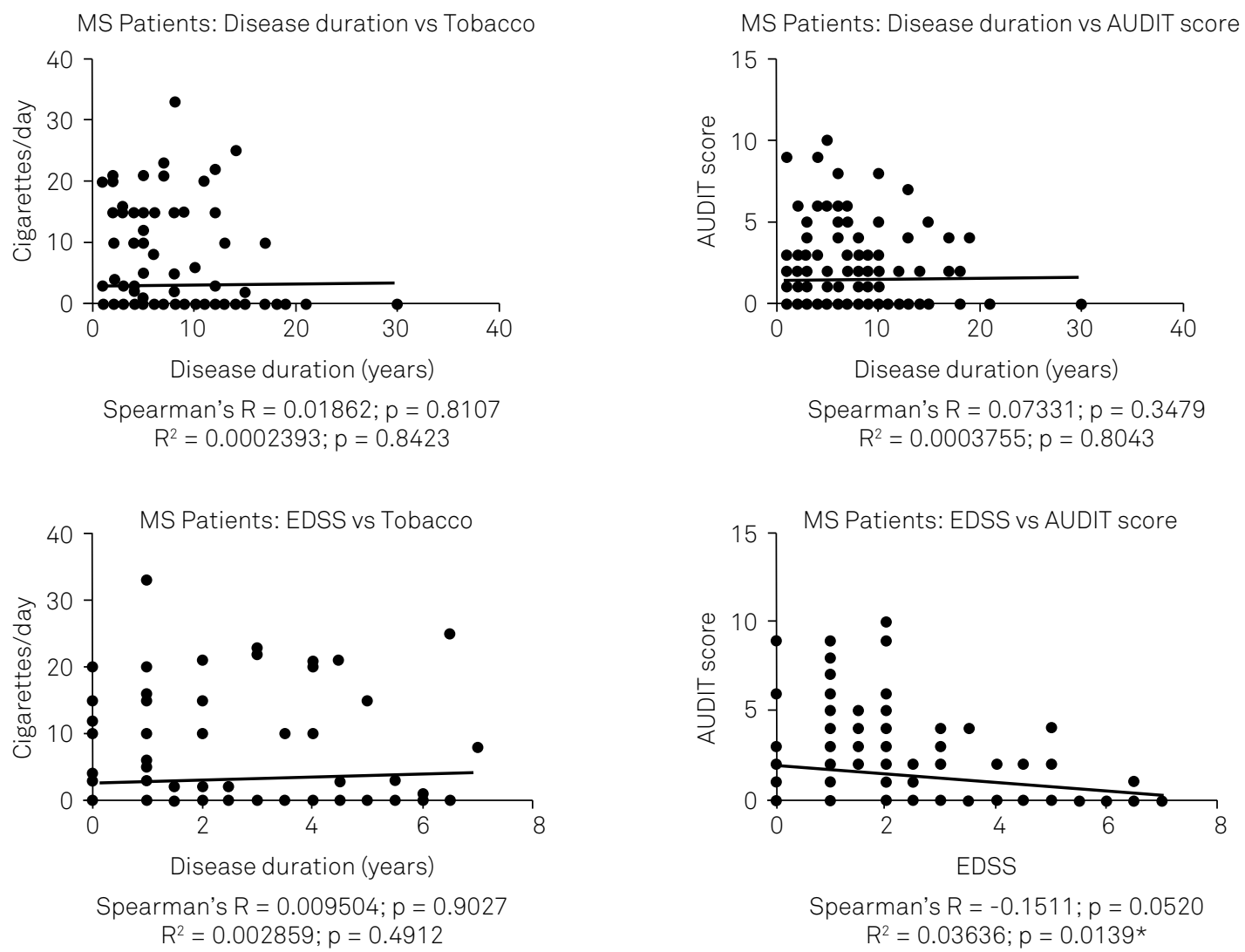

EDSS: expanded disability scale score; AUDIT:Alcohol Use Disorder Identification Test.

Figure 2. Correlation between disease duration and disability (assessed by EDSS) and the tobacco or alcohol use by 168 patients with multiple sclerosis (MS). Patients with higher degrees of disability drank less alcohol $(p=0.01)$. No other correlation was found. 
from age or gender on the use of alcohol, tobacco or illicit drugs in either of the groups. The presence of depression was correlated with higher use of alcohol ( $p=0.04)$ among the control subjects, but this was not found among the patients.

Patients with MS and higher disability levels, as measured using EDSS, made significantly less use of alcohol ( $p=0.01$ ). Patients with higher disability had more depression than did patients with lower levels of EDSS values ( $p=0.003$ ). No specific DMD was correlated with higher use of alcohol or tobacco. Changes to DMD (which might be considered indicative of greater difficulty in achieving disease control) were not associated with the intake of alcohol or tobacco.

Age, gender and socioeconomic level were not correlated to alcohol intake or smoking for patients with MS or for control subjects.

Figures 1 to 5 summarize the above data. All p values are shown in the figures.

\section{DISCUSSION}

The present study did not confirm the findings of misuse of alcohol or tobacco by patients with MS. In fact, the control subjects made higher use of alcohol than did the patients and, when asked about alcohol during our interviews, many patients mentioned that "you are not supposed to drink if you have MS". Our results are completely different from those found in the USA ${ }^{10,12,13}$ and Australia ${ }^{18}$, but our method was also different. While those studies comprised survey questionnaires sent to large populations of patients with MS, ours was a case-control study with individual interviews. It might be argued that patients could be inhibited from talking freely about unhealthy behavioural patterns during an interview but, in fact, their use of alcohol, drugs and smoking were already written in their medical records. The information was just confirmed and quantified during the interviews. A study on patients with MS in Canada ${ }^{11}$ who were individually interviewed also showed high alcohol intake, but that was not a case-control study. The number of patients involved in the studies was also different. In addition, it is possible that the recommendation to avoid alcohol intake while undergoing medical treatment might have positively influenced the health habits of the patients.

The patients with MS in the present study were mostly women, had low levels of disability, were relatively young and typically were not depressed. Relapsing-remitting MS was very frequent in this population of patients, the progressive forms
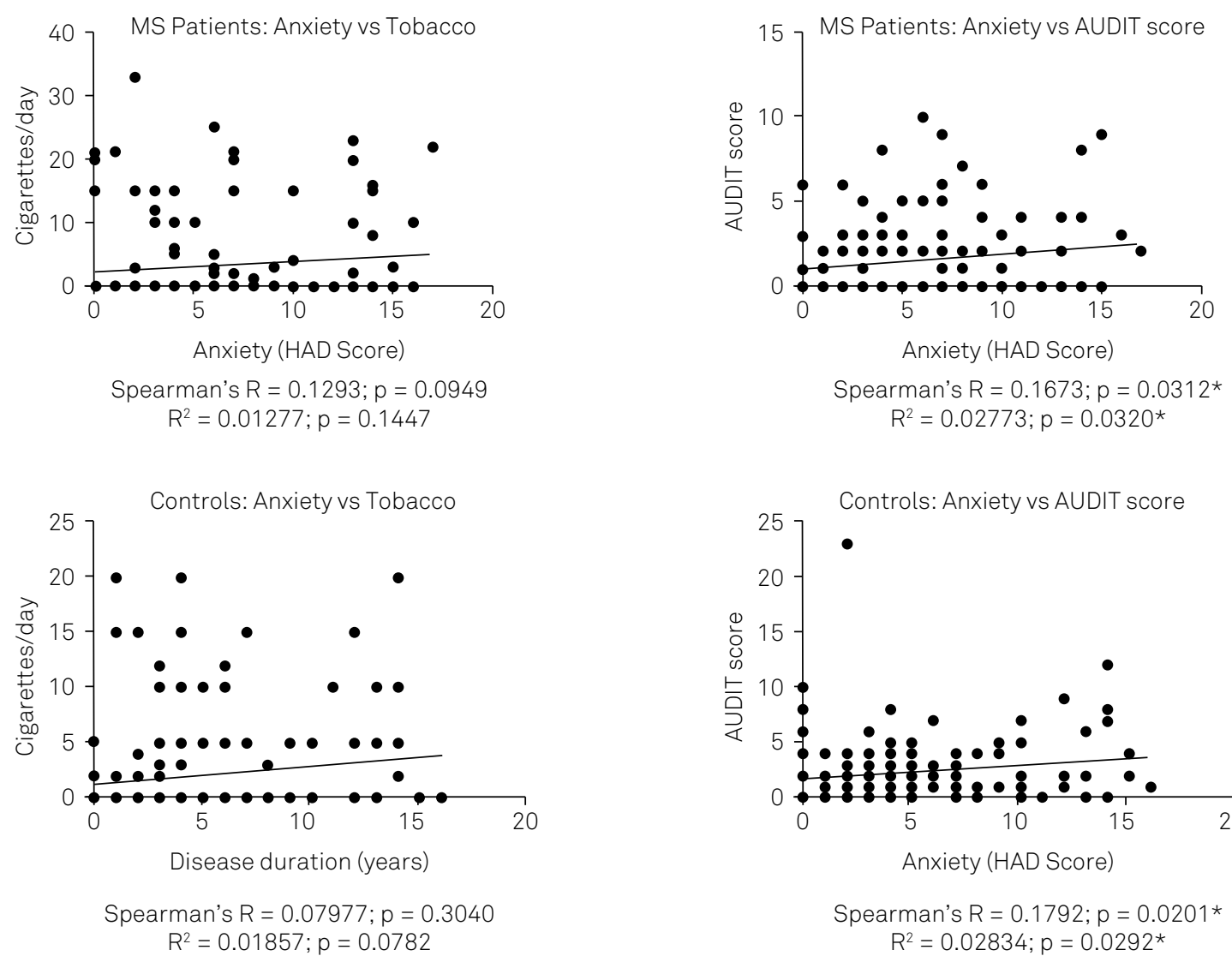

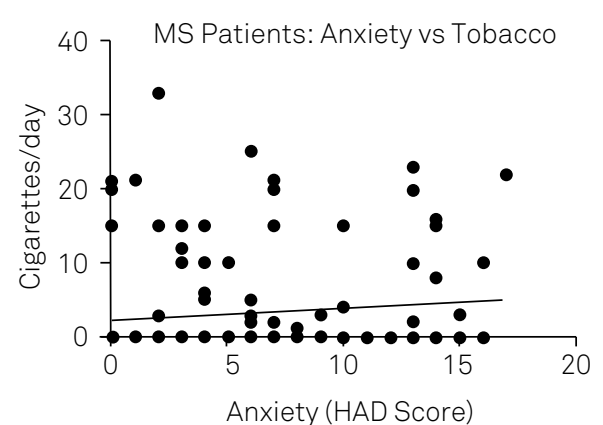

Spearman's $\mathrm{R}=0.1293 ; \mathrm{p}=0.0949$

$R^{2}=0.01277 ; p=0.1447$

$R^{2}=0.01857 ; p=0.0782$

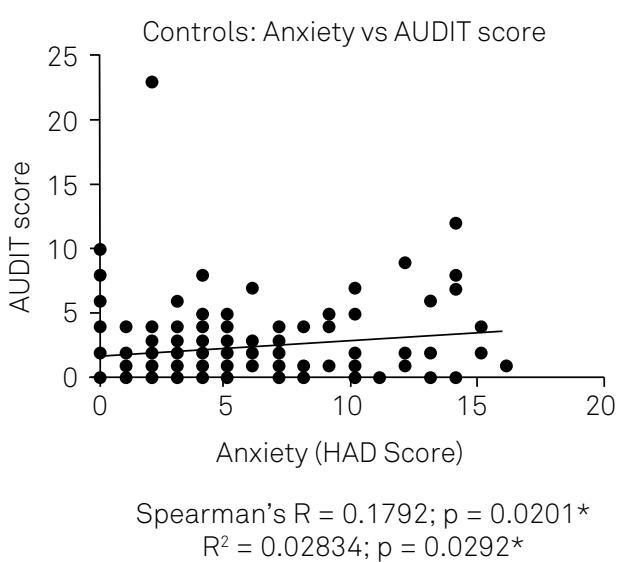

AUDIT: Alcohol Use Disorder Identification Test; HAD: Hospital Anxiety and Depression Scale.

Figure 3. Correlation of anxiety to the use of alcohol or tobacco in 168 patients with multiple sclerosis (MS) and 168 control subjects matched for gender, age and socioeconomic level. The alcohol consumption was positively correlated to anxiety for both patients $(p=0.02)$ and controls $(p=0.03)$. 


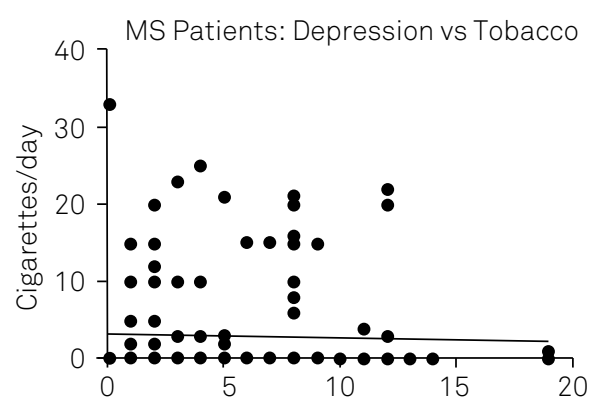

Depression (HAD Score)

Spearman's $R=-0.01755 ; p=0.8213$

$R^{2}=0.0008315 ; p=0.7106$

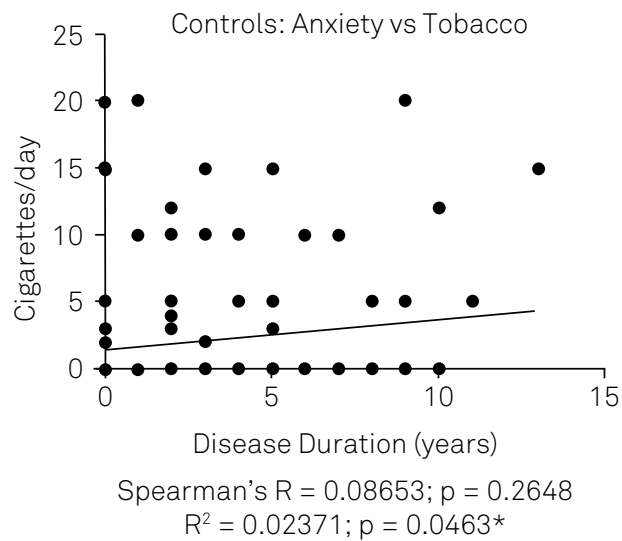

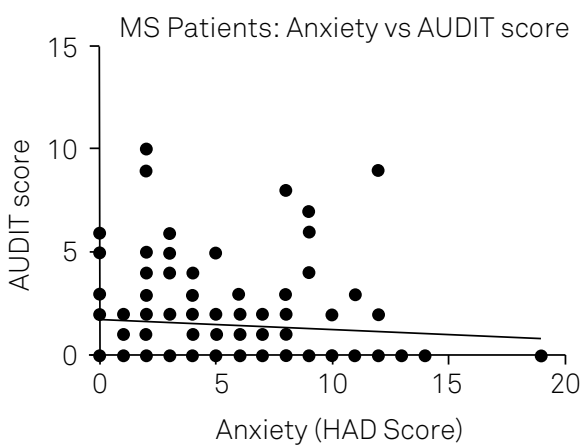

Spearman's $R=-0.09091 ; p=0.2441$

$R^{2}=0.008042 ; p=0.2506$

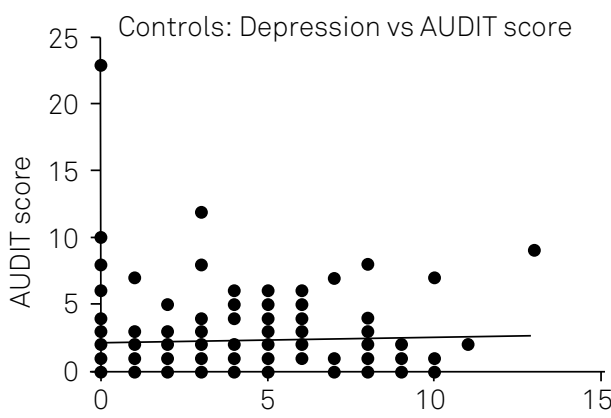

Depression (HAD Score)

Spearman's $R=0.07502 ; p=0.3338$

$R^{2}=0.002101 ; p=0.5552$

AUDIT: Alcohol Use Disorder Identification Test; HAD: Hospital Anxiety and Depression Scale.

Figure 4. Correlation of depression to the use of alcohol or tobacco in 168 patients with multiple sclerosis (MS) and 168 control subjects matched for gender, age and socioeconomic level. Smoking was significantly higher in control subjects only $(p=0.04)$.

MS Patients: Alcohol vs EDSS

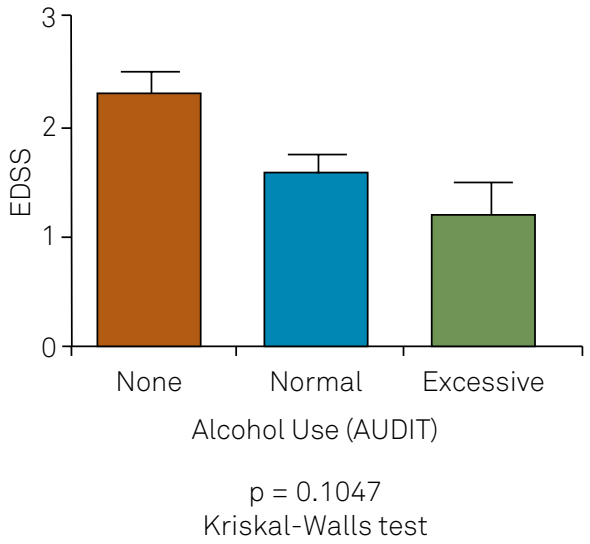

MS Patients: Anxiety vs EDSS

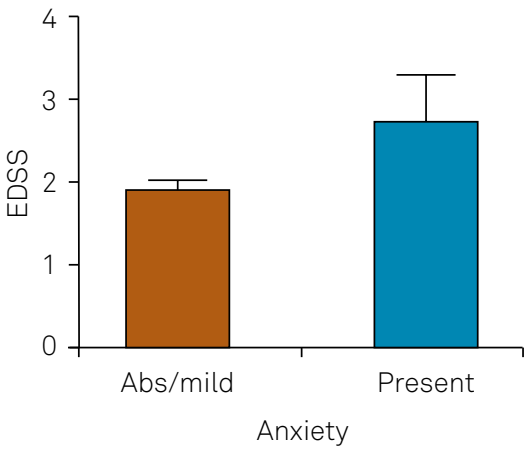

$p=0.2107$

Mann-Whitney test
MS Patients: Depression vs EDSS

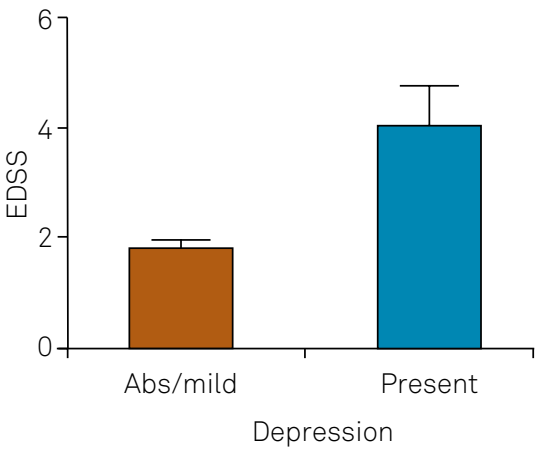

$p=0.0034$ **

Mann-Whitney test

EDSS: expanded disability scale score; AUDIT: Alcohol Use Disorder Identification Test.

Figure 5. Correlation of disability levels (assessed by EDSS) with the use of alcohol, anxiety and depression by 168 patients with multiple sclerosis (MS). Patients with higher degrees of disability were significantly more depressed $(p=0.003)$.

of MS being under-represented in our study. This is a typical finding in an outpatient environment, when patients with MS go for consultations and prescriptions on a regular basis. Those who are more limited or have progressive disease usually do not attend consultations and prefer homecare. Although these facts might have altered the results, no relationships were found between gender, disability, age, depression and alcohol consumption. The only significant factor related to alcohol intake was the presence of anxiety, but this was not different between patients and controls. It is a well-known fact that anxiety and alcohol-related disorders are comorbidities ${ }^{19,20}$ and this might explain the findings of the present study. 
Alcohol consumption was not correlated to a depressive mood. Even with the higher levels of depression among patients with MS than among controls, the correlation between depression and tobacco was found only among the controls. It must be stated that the HAD scale is not the ideal tool for assessing depression, being mostly used as a screening method for mood disorders. For the purpose of the present study, however, HAD was considered to suffice.

Regarding smoking, while many studies have confirmed the relationship between tobacco use and the risk of developing $\mathrm{MS}^{21}$, there are no studies concentrating on the prevalence of smoking among patients with the diagnosis of MS. In the present study, both patients and controls had similar frequencies of tobacco use, although the patients tended to smoke fewer cigarettes a day. Again, when asked about smoking, most patients reported that "smoking was bad for MS" and they had cut down or stopped the habit.

The potential influence of cultural habits must be considered. Not only the methods used in the present study and the number of subjects were different, but the population also was also completely different from the North Americans or Australians studies. Attitudes towards alcohol or tobacco may differ among these countries and, while the present results are different from others, all results may be correct for their specific population. For example, Brazilian neurologists may have reinforced the concept that patients should avoid drinking alcohol due to the disease and the drugs they were using, and this may have affected the outcome in this population. These findings reinforce the fact that results from studies involving habits and lifestyle of one continent cannot simply be "transplanted" to patients from a different part of the world.

In conclusion, findings from studies on hazardous lifestyle behaviour may reflect cultural influences. Results relating to patients with MS cannot be extrapolated from one country or continent to another with the assumption that patients will have similar behaviour. At least for the population of patients investigated in the present study, higher consumption of alcohol or, tobacco was not confirmed.

\section{References}

1. Deangelis TM, Miller A. Diagnosis of multiple sclerosis. Handb Clin Neurol. 2014;122:317-42. 10.1016/B978-0-444-52001-2.00013-3

2. Viner R, Fiest KM, Bulloch AG, Williams JV, Lavorato $\mathrm{DH}$, Berzins $\mathrm{S}$ et al. Point prevalence and correlates of depression in a national community sample with multiple sclerosis. Gen Hosp Psychiatry. 2014;36(3):352-4. doi:10.1016/j.genhosppsych.2013.12.011

3. Nagaraj K, Taly AB, Gupta A, Prasad C, Christopher R. Prevalence of fatigue in patients with multiple sclerosis and its effect on the quality of life. J Neurosci Rural Pract. 2013;4(3):278-82. doi:10.4103/0976-3147.118774

4. Poder K, Ghatavi K, Fisk JD, Campbell TL, Kisely S, Sarty I et al. Social anxiety in a multiple sclerosis clinic population. Mult Scler. 2009;15(3):393-8. doi:10.1177/1352458508099143

5. Benito-León J, Labiano-Fontcuberta A, Mitchell AJ, Moreno-García S, Martínez-Martín P. Multiple sclerosis is associated with high trait anger: a case-control study. J Neurol Sci. 2014;340(1-2):69-74. doi:10.1016/j.jns.2014.02.029

6. Gaskill A, Foley FW, Kolzet J, Picone MA. Suicidal thinking in multiple sclerosis. Disabil Rehabil. 2011;33(17-18):1528-36. doi:10.3109/09638288.2010.533813

7. Bryson CL, Au DH, Sun H, Williams EC, Kivlahan DR, Bradley KA. Alcohol screening scores and medication nonadherence. Ann Intern Med. 2008;149(11):795-804. doi:10.7326/0003-4819-149-11-200812020-00004

8. Hedström AK, Hillert J, Olsson T, Alfredsson L. Alcohol as a modifiable lifestyle factor affecting multiple sclerosis risk. JAMA Neurol. 2014;71(3):300-5. doi:10.1001/jamaneurol.2013.5858

9. Marrie R, Horwitz R, Cutter G, Tyry T, Campagnolo D, Vollmer T. High frequency of adverse health behaviors in multiple sclerosis. Mult Scler. 2009;15(1):105-13. doi:10.1177/1352458508096680

10. Bombardier CH, Blake KD, Ehde DM, Gibbons LE, Moore D, Kraft GH. Alcohol and drug abuse among persons with multiple sclerosis. Mult Scler. 2004;10(1):35-40. doi:10.1191/1352458504ms989oa

11. Quesnel S, Feinstein A. Multiple sclerosis and alcohol: a study of problem drinking. Mult Scler 2004;10(2):197-201. doi:10.1191/1352458504ms992oa
12. Turner AP, Hawkins EJ, Haselkorn JK, Kivlahan DR. Alcohol misuse and multiple sclerosis. Arch Phys Med Rehabil. 2009;90(5):842-8. doi:10.1016/j.apmr.2008.11.017

13. Beier M, D'Orio V, Spat J, Shuman M, Foley FW. Alcohol and substance use in multiple sclerosis. J Neurol Sci. 2014;338(1-2):122-7. doi:10.1016/j.jns.2013.12.029

14. Hasin DS, Stinson FS, Ogburn E, Grant BF. Prevalence, correlates, disability, and comorbidity of DSM-IV alcohol abuse and dependence in the United States: results from the National Epidemiologic Survey on Alcohol and Related Conditions. Arch Gen Psychiatry. 2007;64(7):830-42. doi:10.1001/archpsyc.64.7.830

15. Zigmond, AS, Snaith, RP. The hospital anxiety and depression scale. Acta Psychiatr Scand. 1983;67(6):361-70. doi:10.1111/j.1600-0447.1983.tb09716.x

16. Saunders JB, Aasland OG, Babor TF, de la Fuente JR, Grant M. Development of the Alcohol Use Disorders Identification Test (AUDIT): WHO Collaborative Project on Early Detection of Persons with Harmful Alcohol Consumption--II. Addiction. 1993;88(6):791-804. doi:10.1111/j.1360-0443.1993.tb02093.x

17. Kurtzke JF. Rating neurologic impairment in multiple sclerosis: an expanded disability status scale (EDSS). Neurology. 1983;33(11):1444-52. doi:10.1212/WNL.33.11.1444

18. Weiland TJ, Hadgkiss EJ, Jelinek GA, Pereira NG, Marck CH, van der Meer DM. The association of alcohol consumption and smoking with quality of life, disability and disease activity in an international sample of people with multiple sclerosis. J Neurol Sci. 2014;336(1-2):211-9. doi:10.1016/j.jns.2013.10.046

19. Morris EP, Stewart SH, Ham LS. The relationship between social anxiety disorder and alcohol use disorders: a critical review. Clin Psychol Rev. 2005;25(6):734-60. doi:10.1016/j.cpr.2005.05.004

20. Cooper R, Hildebrandt S, Gerlach AL. Drinking motives in alcohol use disorder patients with and without social anxiety disorder. Anxiety Stress Coping. 2014;27(1):113-22. doi:10.1080/10615806.2013.823482

21. Handel AE, Williamson AJ, Disanto G, Dobson R, Giovannoni G, Ramagopalan SV. Smoking and multiple sclerosis: an updated meta-analysis. PLoS One. 2011;6(1):e16149. doi:10.1371/journal. pone.0016149 